\title{
Cooperative Cataloging, Vendor Records, and European Language Monographs Charlene Kellsey
}

The appearance in OCLC and RLIN of minimal level catalog records from European book vendors for European language monographs and their effect on cataloging department workflows and cooperative cataloging efforts have been matters of concern expressed recently at ALA meetings and in the library literature. A study of 8,778 catalog records was undertaken to discover how many current European language monographs were being cataloged by the Library of Congress, by member libraries, and by vendors. It was found that vendor records accounted for 16.7\% of Spanish books, 18\% of French books, 33.6\% of German books, and $52.5 \%$ of those in Italian. The number of libraries enhancing vendor records in OCLC was found to be only approximately one-third the number of libraries contributing original records for European language books. Ongoing increases in European book publishing and the increasing globalization of cataloging databases mean that the results of this study have implications not only for local cataloging practice but for cooperative cataloging as a whole.

Charlene Kellsey (kellseycz@glinda. colorado.edu) is Assistant Professor, Monographic Cataloger, and Classics Bibliographer at the University of Colorado at Boulder Libraries.

Manuscript received February 18, 2002; accepted April 22, 2002.
Cooperative cataloging, or the sharing of the work of creating catalog records $\checkmark$ for books being added to libraries' collections, has been important to librarianship for a long time. It began with the distribution of catalog card sets by the Library of Congress (LC) in the early twentieth century and accelerated in the 1970s with the development of online databases, such as OCLC and RLIN, to which members could contribute original records. The ideal of cooperative cataloging has been to create a catalog record for any given book only once and then share the record with other libraries that need it, thus eliminating duplication of effort and diminishing the amount of original cataloging that any single library would have to do. The development of the Program for Cooperative Cataloging (PCC) in the 1990s was a successful effort to guarantee a standard level of quality in the records contributed by participants at the same time encouraging the contribution of larger numbers of high quality records.

A new development, however, seems to be undermining some of the progress in cooperative cataloging that has benefited libraries to date. Beginning in 1996, OCLC and RLIN began loading minimal level catalog records from several European book vendors into their databases. A number of articles in the library literature recently have raised questions about the value of these minimal level vendor catalog records for European language monographs and their effect on catalog department workflows and national cooperative cataloging efforts (Beall 2000; Shedenhelm and Burk 2001). OCLC maintains that its database, WorldCat, is not just a cataloging database anymore. Vendor 
records are valuable for the acquisitions process and useful to reference librarians trying to identify the existence of a title for their patrons (OCLC 2002). Vendor records are basically brief acquisition records that do not contain classification numbers or subject headings, and although catalogers at the Casalini Libri firm have recently been trained by a Library of Congress representative in the LC classification and subject heading systems, their enhanced catalog records will only be available to customers for an extra charge; they will not be available through the utilities (Casalini 2002). In defense of the vendors, it is really not their responsibility to provide full cataloging records for the books they sell; hiring catalogers to do this incurs costs that vendors, as businesses, need to recover. In fact, Casalini Libri estimates that they will charge two Euros per enhanced record (approximately \$1.80). While this may seem like a bargain to many libraries, it must be remembered that these records still will not meet the standards for full level U.S. records. The larger concern about delegating a heretofore public cooperative activity to private companies also needs to be addressed. Thus the effect on cooperative cataloging of vendor records in the databases needs to be documented and understood so that the library cataloging community can effectively respond to the changes these records have generated in cataloging work processes. The present study is intended to begin that documentation in order to inform the discussion of problems and possible solutions.

The effect of vendor records on cataloging department processes has several aspects. Since the vendor records do not contain classification numbers or subject headings, and name and series headings often do not match the form of heading found in the U.S. national authority file, the records require almost as much work by catalogers as creating an original record. Books for which a vendor record is found in OCLC or RLIN, however, often go to the copy cataloging unit, where time and effort may be spent to determine that the item needs the attention of an original cataloger. The time and effort required of original catalogers to upgrade a minimal level vendor record may be similar to that required to create a new record but the effect on costs to their institution may be different, and many libraries that are allowed to add new records to a national database such as OCLC may not be authorized to enhance existing records. The result of this situation would seem to be that more libraries would download vendor records and upgrade them in-house before adding them to their catalogs, which anecdotal evidence suggests is happening. Fewer libraries would then be contributing full level catalog records to the national databases and more libraries would be duplicating the effort of upgrading the records in-house, thus undermining the cooperative cataloging that benefits all libraries as well as the companies to which many libraries outsource their cataloging.
A recent retrospective study of Italian monographs documents the trend of an increasing number of vendor records for Italian monographs in OCLC at the expense of member-contributed records (Kellsey 2001). That study found that, in 2000, 60\% of records for books in Italian were contributed to OCLC by a vendor while $30 \%$ were contributed by LC and only $10 \%$ by member libraries. This was a significant change from 1996 when $24 \%$ percent of records for Italian books were contributed by LC and $76 \%$ by member libraries. The current study expands that investigation to include French, German, and Spanish language monographs, in addition to Italian, and covers a variety of subject areas in order to determine whether the results of that earlier study remain valid when larger numbers of records are examined. If vendor records represent an increasing percentage of catalog records for European language monographs, then it would also be important to know how many libraries contribute original records and how many upgrade vendor records in OCLC, so the study also collected that information.

\section{Method}

The online catalog of the University of Colorado at Boulder Libraries was used to gather the data for this study. The UCB Libraries is a member of the Association of Research Libraries, with holdings of more than three million volumes (not including documents, microforms and special collections) and annual acquisitions of approximately 30,000 new monographic volumes. Around 22,000 undergraduate students and 4,000 graduate students are registered. Ph.D. programs exist in all of the subject areas represented in this study except German, which offers an MA, and Italian, which offers a BA. The libraries receive approval slips from Otto Harassowitz, Casalini Libri, Blackwell's, and Aux Amateurs du Livre, so active ordering of western European language monographs is a regular part of the acquisitions program. The Cataloging Department participates in OCLC's Enhance program and the Program for Cooperative Cataloging's Name Authority Cooperative program (NACO), Subject Authority Cooperative program (SACO), and Bibliographic Cooperative program (BIBCO). It is Cataloging Department policy to enhance minimal level records in OCLC before exporting them to the local catalog.

To gather data for this study, the "Create Lists" function of the Innovative Interfaces online system in the UCB Libraries was used to collect records of books cataloged in 1999 and 2000 in a number of different call number areas. They included: B (philosophy), D (general European history), DC (history of France), DD (history of Germany), DF (history of Greece), DG (history of Italy), DP (history 
of Spain), DT (history of Africa), F 1201-3799 (history of Latin America), PA (classics), PQ (French, Italian, and Spanish literature), and PT (German literature). The lists generated were then sorted by language and by the library codes found in the MARC tag 040 (cataloging source) and then manually tabulated to discover the number of records originally contributed to OCLC by the Library of Congress, by member libraries, and by European book vendors for English, French, German, Italian, and Spanish language monographs. The vendors were Casalini Libri, Iberbook International, Otto Harrassowitz, Puvill Libros, and Jean Touzot.

After the initial tabulation of the number of records input by each category (LC, member, and vendor), a further tabulation was done of how many member libraries were contributing new records and how many were enhancing vendor records for European language monographs. Since concern has been expressed in the literature and at ALA meetings that the appearance of large numbers of vendor records in the national databases may be having an effect on the cooperative cataloging efforts of member libraries, documenting the current state of cooperative cataloging seemed crucial. Recommendations for change, whether locally or nationally, need to be based on accurate knowledge of current practice.

The tabulation of member library contributions and enhancements was done by creating charts of all the library code symbols in subfield $\$$ a of the 040 MARC tag, which represents the library that initially created the record. The number of occurrences of that code were then counted for each language. In order to determine how many libraries were upgrading vendor records, the first code appearing in subfield $\$ \mathrm{~d}$ was counted for records that had a vendor's symbol in the subfield $\$ \mathrm{a}$. Although often more than one code appears in subfield $\$ \mathrm{~d}$, representing other libraries that have modified the record in some way, in OCLC it is impossible to tell what a particular library has done to the record. Based on cataloging experience, it seems that the first library to modify the record usually adds a call number, verifies the name and series headings, and adds one or more subject headings. Although other libraries may add a call number from a different scheme or additional subjects, most of the critical work has been done by the first library, so it was decided only those would be counted.

Records already in the UCB catalog were used for this investigation, rather than trying to capture information as books passed through the catalog workflow, for several reasons. One was to avoid interruption of the workflow in a large and busy cataloging department. More significant, however, was the importance of gathering a large set of data in order to improve the reliability of conclusions drawn from it. By selecting all the records in several call number areas for the two most recently completed cataloging years, it was possible to analyze information from 8,778 records in a matter of months, rather than having to wait for enough new items to come in, at irregular intervals, to gather a large amount of data. The call number areas chosen represent European literature, history, and area studies as well as the humanities fields of classics and philosophy. These fields were selected as being the most likely to have significant numbers of European language monographs on which to base the study.

\section{Results}

Table 1 represents the number of records for monographs in English versus those in European languages (French, German, Italian, and Spanish) for the subject areas examined. Although the percentages in each language vary greatly by subject area, and the amount of Spanish literature received by UCB may be unusually large, it can be seen from the totals that more than half of the monographs purchased by UCB in these areas are not in English. Since the data in table 2 show that the Library of Congress catalogs only $23-38 \%$ of European language monographs, versus almost $75 \%$ of English language monographs in these areas, it is clear that European language monographs represent a significant cataloging workload for those libraries collecting them.

In fact, one of the motivating factors for the development of the National Coordinated Cataloging Program (precursor to the Program for Cooperative Cataloging) was the Library of Congress's need for help in getting cataloging done for European language materials. The initial participants were assigned subject areas for which they would contribute records, almost all of which were in area studies, literature, and humanities in Spanish, German, French, and Italian (Rosenblatt 1993). This need appears not to have diminished.

The number of vendor records varies quite a bit by language, from a low of $16.7 \%$ for Spanish books to a high of $52.5 \%$ for those in Italian, reflecting the contribution of records by the different vendors (table 2). Because a much larger number of books in Spanish are received, however, the actual number of vendor records for Spanish books is larger than for the other three languages.

Tables 3 and 4 show the number of libraries contributing original records for European language monographs versus the number upgrading vendor records in OCLC. Totals for each column were not included since many libraries contributed or enhanced records in more than one language. As can be seen when comparing the tables, many fewer libraries upgrade records than contribute original records. One of the surprising findings of this part of the study was the large number of libraries that contribute five 
Table 1. Number of Monographs in English and European Languages, Cataloged at University of Colorado, Boulder, 1999-2000

\begin{tabular}{|c|c|c|c|c|c|}
\hline Classification & $\begin{array}{l}\text { English } \\
\text { Language }\end{array}$ & $\%$ & $\begin{array}{l}4 \text { European } \\
\text { Languages }\end{array}$ & $\%$ & $\begin{array}{c}\text { Total } \\
\text { Monographs }\end{array}$ \\
\hline B & 840 & 83.9 & 161 & 16.0 & 1,001 \\
\hline $\mathrm{D}$ & 769 & 91.2 & 74 & 8.8 & 843 \\
\hline DC & 152 & 77.0 & 45 & 22.8 & 197 \\
\hline DD & 110 & 60.0 & 73 & 40.0 & 183 \\
\hline DF & 79 & 70.5 & 33 & 29.5 & 112 \\
\hline DG & 199 & 49.6 & 202 & 50.4 & 401 \\
\hline DP & 67 & 36.0 & 119 & 64.0 & 186 \\
\hline DT & 324 & 95.3 & 16 & 4.7 & 340 \\
\hline $\mathrm{F}$ & 357 & 52.2 & 327 & 47.8 & 684 \\
\hline PA & 270 & 46.2 & 315 & 53.8 & 585 \\
\hline PQ (Fre) & 377 & 32.3 & 790 & 67.7 & 1,167 \\
\hline PQ (Ital) & 101 & 52.3 & 92 & 47.7 & 193 \\
\hline PQ (Spa) & 209 & 10.3 & 1826 & 89.7 & 2,035 \\
\hline PT & 197 & 23.1 & 654 & 76.9 & 851 \\
\hline Totals & 4051 & 46.1 & 4727 & 53.9 & 8,778 \\
\hline
\end{tabular}

Table 2. Source of Cataloging for English and European-Language Monographs, 1999-2000

\begin{tabular}{lrrrrrrr}
\hline & LC & $\%$ & Member & $\%$ & Vendor & $\%$ & $\begin{array}{c}\text { Total } \\
\text { Records }\end{array}$ \\
English & 3,026 & 74.7 & 996 & 24.6 & 29 & 0.7 & 4,051 \\
French & 229 & 25.3 & 514 & 56.7 & 163 & 18.0 & 906 \\
German & 237 & 22.8 & 453 & 43.6 & 350 & 33.6 & 1,040 \\
Italian & 122 & 25.7 & 103 & 21.7 & 249 & 52.5 & 474 \\
Spanish & 869 & 37.7 & 1,052 & 45.6 & 386 & 16.7 & 2,307 \\
Total foreign & 1,457 & 30.8 & 2,122 & 44.9 & 1,148 & 24.3 & 4,727 \\
Total & 4,483 & 51.0 & 3,118 & 35.5 & 1,177 & 13.4 & 8,778 \\
\hline
\end{tabular}

or fewer original records in these four languages. This would seem to indicate that many libraries, while not contributing large numbers of records for foreign language books, do contribute a few records for items they receive that do not yet have a record in OCLC, in the spirit of cooperative cataloging. The fact that only roughly a third as many libraries enhance vendor records in OCLC, as shown in table 4, certainly indicates a loss of some of the benefits of cooperative cataloging. Further study of the libraries that contribute original records but do not enhance records would be useful in order to identify barriers to upgrading records and possible incentives that would encourage more libraries to upgrade records for the benefit of all.

\section{Discussion}

With the exception of the preliminary study noted previously, there have not been any previous quantitative studies of vendor records in OCLC (Kellsey 2001). There have, however, been a few previous studies of the avail- ability of LC and member records in OCLC. Metz and Espley (1980) studied 396 monographs received at [Virginia Polytechnic Institute and State University] and Struble and Kohlberger (1987) studied 7,062 items at the University of Pittsburgh. Both studies were concerned with the availability of cataloging copy in OCLC on receipt of the books and after different periods of time in order to optimize the cataloging workflow and minimize multiple searching for the same item. Although the goals of those earlier studies differed from the current study, it is possible to extrapolate some comparable data from their tables to provide a view of the availability of LC and member records over a period of twenty-one years.

Table 5 illustrates the source of catalog records found in the three studies. Several caveats should be kept in mind when interpreting this table. Metz and Espley selected their books into groups of American imprints, British imprints and other foreign imprints by a ratio of 4:2:1 and since their total number of books was small (396), they looked at only 58 foreign imprints. Since the current study did not separate British imprints from U.S. imprints, but included them in the English language category, and Metz and Espley only gave percentages, not numbers of items, in their tables, there was no way to calculate their inclusion, so they have been omitted from table 5. Metz and Espley also did not specify countries included in foreign imprints, so this category may have included languages in addition to the four in the current study. The percentages for LC copy were taken from table 3 of Metz and Espley's study, and the percentage of member copy was inferred from this (which would include any original cataloging their library may have had to do).

The study of Struble and Kohberger notes that they excluded Slavic materials, and their tables include a breakdown by the four languages used in this study (although they included Portuguese with Spanish). The author of the current study calculated the percentages in table 5 from the numbers of items listed by Struble and Kohberger in their charts. In calculating the percentages, items with no copy at the end of the study were included with the member copy since presumably the study library would have had to then catalog them. 
It is interesting to note the close similarity in percentages of LC records for English language books between the 1980 and 2002 studies. The increase in LC records for foreign books from $22.4 \%$ to $30.8 \%$ was also noted from 1996 to 2000 in the study of Italian monographs (Kellsey 2001). The higher percentages of LC records for both English and foreign books in the 1987 study may have been due to several causes. The 1987 study included all imprint dates received during the study period, and while most of the books had recent imprints, a not insignificant number had imprint dates four or more years old, allowing more time for LC copy to appear. The 1980 study included only the previous two years' imprints. The current study did not examine imprints, but since the cataloging backlog at UCB is negligible and acquisitions emphasize current imprints, most of the items likely had imprints in the last several years. It should also be noted that while the 1987 study and current study had a comparable sample size, two-thirds of the books in the 1987 study were in English and only one-third were in foreign languages. In the current study, $46 \%$ of the books were in English and $54 \%$ were in foreign languages, so while the differences found in the two studies could be due to a genuine increase in LC cataloging in the late 1980s, which has since declined, they could be due simply to differences in collecting with concomitant variations in copy availability. Further studies using additional libraries and done at periodic intervals would be needed to settle this question.

\section{Implications}

The implications of this study intersect with several developments in the international arena. Worldwide publishing output has been increasing for many years. From 1980 to 1990 it increased 18\% (Reed-Scott 1996); in the 1990s increases in book publishing continued in most European countries (UNESCO 1999). OCLC reports that for the period 1988-1994, 59.3\% of foreign titles cataloged by OCLC libraries were from western Europe (Reed-Scott 1996). Obviously, the need for cataloging western European monographs is not about to disappear in the near future. In fact, the goal of the Global Resources Project, jointly sponsored by the Association of Research Libraries (ARL) and the Association of American Universities (AAU), is to increase the acquisition of unique materials from targeted areas by American university libraries. Although several of the projects deal with Asian publications, the Latin Americanist Research Resources Project targets publications in Spanish from Argentina and Mexico and the German Demonstration Project targets German language materials (Reed-Scott
Table 3. Number of Member Libraries Contributing Original Records in OCLC for European-Language Monographs, 1999-2000

\begin{tabular}{lrccc}
\hline & & & & $\begin{array}{c}\text { Total } \\
\text { No. of } \\
\text { Libraries }\end{array}$ \\
No. of Records & $\mathbf{1 - 5}$ & $\mathbf{6 - 1 9}$ & $\mathbf{2 0 +}$ & 112 \\
French & 92 & 16 & 4 & 116 \\
German & 100 & 10 & 6 & 48 \\
Italian & 46 & 2 & 0 & 230 \\
Spanish & 193 & 29 & 8 & \\
\hline
\end{tabular}

Table 4. Number of Member Libraries Upgrading Vendor Records in OCLC for European-Language Monographs, 1999-2000

\begin{tabular}{lrrcc}
\hline No. of Records & $\mathbf{1 - 5}$ & $\mathbf{6 - 1 9}$ & $\mathbf{2 0 +}$ & $\begin{array}{c}\text { Total } \\
\text { No. of } \\
\text { Libraries }\end{array}$ \\
French & 31 & 6 & 2 & 39 \\
German & 33 & 12 & 3 & 48 \\
Italian & 35 & 2 & 4 & 41 \\
Spanish & 42 & 10 & 3 & 55 \\
\hline
\end{tabular}

Table 5. Source of Catalog Records for English and Foreign Monographs, 1980-2002 (\%)

\begin{tabular}{|c|c|c|c|c|c|c|}
\hline $\begin{array}{l}\text { Metz and Espley (1980) } \\
\mathrm{N}=396\end{array}$ & $\begin{array}{c}\text { LC } \\
77.6\end{array}$ & $\begin{array}{l}\text { English } \\
\text { Member } \\
{[22.4]}\end{array}$ & Vendor & $\begin{array}{r}\text { LC } \\
22.4\end{array}$ & $\begin{array}{c}\text { Foreign } \\
\text { Member } \\
{[77.6]}\end{array}$ & Vendor \\
\hline $\begin{array}{l}\text { Struble and Kohlberger } \\
\text { (1987) } \\
\mathrm{N}=7062\end{array}$ & 84.4 & 15.6 & & 47.7 & 52.3 & \\
\hline $\begin{array}{l}\text { Kellsey (2002) } \\
\mathrm{N}=8778\end{array}$ & 74.7 & 24.6 & 0.7 & 30.8 & 44.9 & 24.3 \\
\hline
\end{tabular}

1996; see www.arl.org/collect/grp/grp.html for updates on these projects).

Another development involves the encouragement of international participation in the large cataloging databases. OCLC has been actively recruiting international members and contribution of records since the mid-1980s with the specific purpose of reducing duplicate cataloging and encouraging resource sharing (Brown 1992). By 2000, OCLC had participating libraries from 64 countries. With the technical advances in electronic communication in the last few years, it has become easier for libraries around the world to access and contribute to OCLC, and national libraries of several countries have joined this effort, some of them through the PCC program of the Library of Congress (Byrum 2000). These developments represent progress toward one of IFLA's stated goals, that each country should have responsibility for cataloging its own imprints (Holley 1996). At the same time, the introduction of catalog records 
from non-English-speaking countries, from both libraries and vendors, has spotlighted the problems of differing standards in cataloging rules, notes in the language of the country creating the record, and the very thorny problem of lack of a universal authority file for names, corporate bodies, and uniform titles and series. Subject headings also present a challenge, since they need to be in the language of the catalog users, yet strict comparability of terms is often not possible between languages.

Although progress is being made toward developing international solutions to the problems described above, U.S. libraries still need to deal with the current reality of having to modify records for foreign language monographs before incorporating them into their local catalogs. Names and series have to be checked and modified in accordance with the U.S. authority file; notes have to be translated into English; LC subject headings have to be added; and a classification number usually needs to be added, especially if a library uses the LC classification system, since few libraries outside the United States use that system.

In the context of these developments in the larger world of publishing and cataloging, the implications of the results of the current study are troubling. Already an average of $24 \%$ of records for monographs in the four major western European languages are being entered into OCLC by vendors, with higher percentages in German and Italian. This proportion can only increase as more foreign libraries begin to add records also. Although their records may be fuller than the vendor records, they will still need modifications as noted above. At the same time, the number of U.S. libraries that upgrade records for western European language books is only about a third of the number that contribute original records for these books. The result is that more libraries are having to modify the same records locally, rather than one library upgrading a record that others can use, which is the antithesis of the goal of cooperative cataloging.

Identifying this trend is only the first step. Further studies of the practices of libraries that need to catalog western European language books would be helpful as would identifying perceived barriers or lack of incentives to upgrading records in the national databases. Exciting as the progress in international cataloging cooperation and convergence of standards is, we also need to have discussions at all levels on the impact of this globalization of cataloging on local library cataloging practices and workload.

\section{Works Cited}

Beall, Jeffrey. 2000. The impact of vendor records on cataloging and access in academic libraries. Library Collections, Acquisitions, and Technical Services 24: 229-37.

Brown, Rowland C. W. 1992. OCLC involvement in international programs and the impact on academic libraries. In The role of the American academic library in international programs, edited by Bruce D. Bonta and James G. Neal. Greenwich, Conn.: Jai.

Byrum, John D. 2000. The emerging global bibliographic network: The era of international standardization in the development of cataloging policy. In What in the world . . . cataloging on an international scale: Papers from the ALCTS Preconference, June 26, 1998. Library Resources \& Technical Services 44, no, 3: 114-21.

Casalini, Barbara. 2002. Communication at the WESS Research and Planning Committee Meeting, ALA Midwinter Meeting, Jan. 19.

Holley, Robert P. 1996. IFLA and international standards in the area of bibliographic control. In Cataloging and classification standards and rules. New York: Haworth.

Kellsey, Charlene. 2001. Trends in source of catalog records for European monographs 1996-2000. Library Resources \& Technical Services 45, no. 3: 123-26.

Metz, Paul, and John Espley. 1980. The availability of cataloging copy in the OCLC data base. College \& Research Libraries 41: 430-36.

OCLC. 2002. Communication at the OCLC Enhance Sharing Session, ALA Midwinter Meeting, Jan 19.

Reed-Scott, Jutta. 1996. Scholarship, research libraries, and global publishing. Washington, D.C.: Association of Research Libraries.

Rosenblatt, Susan. 1993. The National Coordinated Cataloging Program from the participant's perspective. Cataloging of Classification Quarterly 17, no. 3/4: 189-99.

Shedenhelm, Laura D., and Bartley A. Burk. 2001. Book vendor records in the OCLC database: Boon or bane? Library Resources \& Technical Services 45, no. 1: 10-19.

Struble, Carol A., and Paul B. Kohberger, Jr. 1987. Statistical survey to determine availability of cataloging copy on OCLC. Cataloging \& Classification Quarterly 7, no. 3: 13-22.

UNESCO. 1999. Statistical yearbook. Paris: UNESCO; Lanham, Md.: Bernan. 